\section{"Reflex" Epilepsy}

Marshall Hall ${ }^{1}$ distinguished spontaneous epileptic seizures from those elicited by external stimuli in which there was a presumed disorder of reflex function. The concept of reflex epilepsy was elaborated ${ }^{2}$ until, by the end of the last century, ${ }^{3}$ a major cause of seizures was held to be chronic sensory irritation from such varied causes as worms, phimosis, and refractive errors.

Recently the term has come to be applied more narrowly to fits demonstrably induced by particular stimuli or mental activities and occurring in some $1-6 \%$ of people with epilepsy. ${ }^{4-6}$ The most common modality of sensory precipitation is visual: $20-40 \%$ of epileptics show abnormal electroencephalographic responses to flickering light, ${ }^{78}$ and in $2-4 \%$ seizures can be induced by the laboratory stroboscope or-more importantly-in daily living by sunlight on water, television, discotheques, escalators, and so on. Rarer sensory precipitants include sound, touch, proprioception, and possibly visceral, olfactory, or vestibular stimuli. Less commonly seizures are triggered by a particular mental activity: hearing or performing music, ${ }^{9}$ reading, ${ }^{10}$ writing, ${ }^{6}{ }^{11}$ specific visual or auditory imagery, ${ }^{912} 13$ mathematical calculation, ${ }^{14}$ and in a recent report $^{15}$ sequential decision making under stress.

Many intriguing case histories have been published, and the precise conditions necessary for seizure induction have often been investigated with great ingenuity. The findings suggest that the apparent distinction between external and internal precipitants cannot be maintained. For instance, a simple and highly specific sensory stimulus such as touching a particular part of the body may prove ineffective unless combined with an element of surprise. ${ }^{16}$ Conversely, reading is accompanied by patterned visual and proprioceptive stimuli which could act as triggers, and some patients with reading epilepsy are photosensitive. ${ }^{17}$ Others, however, are affected only by interesting, difficult, or emotionally charged material: ${ }^{18-20}$ in some, reading is but one of several activities associated with language which induce seizures. ${ }^{21}{ }^{22}$ Sometimes the possibility of conditioning arises-for instance, in a safety pin fetishist who had fits when viewing or visualizing a pin ${ }^{12}$ and in two patients with musicogenic seizures who, during the period when their epilepsy developed, habitually used loud music to relieve overwhelming emotions. ${ }^{23}{ }^{24}$

Sometimes a patient has a known lesion of the primary projection area serving the sensory modality which induces the attacks. It is occasionally possible, by measuring the latencies of the sensory evoked potentials and of the electromyographic concomitants of the seizure, to show that there must be rapid conduction of nerve impulses from the sensory cortex to the appropriate motor area by a fairly simple pathway. ${ }^{25}$ One patient has been shown to be sensitive to pattern only in conditions of binocular fusion, suggesting that the trigger mechanism must be situated at or beyond the complex cells of the visual cortex. ${ }^{26}$ However, electrophysiological studies, even in patients sensitive to simple unstructured stimuli such as flicker, do not generally support an explanation in terms of disordered reflex mechanisms. There may be abnormally large cerebral evoked potentials to sensory modalities other than those which induce seizures, ${ }^{27}$ and if paroxysmal activity is elicited this is not usually confined to the appropriate sensory projection area but often has a generalized distribution and resembles the spontaneous discharges of centrencephalic epilepsy. Thus in some respects the cerebral dysfunction appears to be diffuse. Recent com- munications under the title "reflex epilepsy" often concede that the term is inappropriate but fail to suggest a preferable alternative. Here, as in other instances, unsatisfactory terminology reflects the present lack of understanding. Nevertheless, this disorder is not of interest only to the collector of clinical exotica: the marked specificity of the percepts or cognitive states required to precipitate seizures in some patients suggests that further study might provide a valuable insight into physiological mechanisms underlying mental activities.

${ }^{1}$ Hall, M., Philosophical Transactions, 1833, 123, 635.

2 Brown-Sequard, E., Researches on Epilepsy. Boston, David Clapp, 1857.

3 Ranney, A., Nervous Diseases. Philadelphia, Davis, 1888.

${ }^{4}$ Servit, Z., et al., in Reflex Mechanisms in the Genesis of Epilepsy, ed. Z. Servit. Amsterdam, Elsevier, 1963.

5 Gastaut, H., and Tassinari, C. A., Epilepsia, 1966, 7, 85.

6 Symonds, C., Brain, 1959, 82, 133.

7 Stevens, J. R., Archives of Neurology, 1962, 7, 330

8 Gastaut, H., Trevisan, C., and Naquet, R., Electroencephalography and Clinical Neurophysiology, 1958, 10, 194.

${ }^{9}$ Critchley, M., Brain, 1937, 60, 13.

10 Bickford, R. G., Fournal of the Michigan Medical Society, 1954, 53, 1018.

11 Asbury, A. K., and Prensky, A. L., Transactions of the American Neurological Association, 1963, 88, 193.

${ }^{12}$ Mitchell, W., Falconer, M. A., and Hill, D., Lancet, 1954, 2, 626.

${ }^{13}$ Stubbe Teglbjaerg, H. P., Acta Psychiatrica et Neurologica, 1949, 24, 679.

14 Ingvar, D. H., and Nyman, G. E., Neurology, (Minneapolis), 1962, $12,282$.

15 Forster, F. M. et al., Archives of Neurology, 1975, 32, 54.

${ }^{16}$ Calderon-Gonzales, R., Hopkins, I., and McLean, W. T., fournal of the American Medical Association, 1966, 198, 521.

17 Rowan, A. J., Heathfield, K. W. G., and Scott, D. F., fournal of Neurology, Neurosurgery and Psychiatry, 1970, 33, 476.

18 Alajouanine, Th., Nehlil, J., and Gabersek, V., Revue Neurologique, 1959, $101,463$.

19 Stevens, H., New England fournal of Medicine, 1957, 257, 165.

${ }^{20}$ Critchley, M., Cobb, W., and Sears, T. A., Epilepsia, 1959, 1, 403.

${ }^{21}$ Geschwind, N., and Sherwin, I., Archives of Neurology, 1967, 16, 25.

${ }^{22}$ Forster, F. M., and Daly, R. F., Transactions of the American Neurological Association, 1973, 98, 186.

${ }^{23}$ Shaw, D., and Hill, D., fournal of Neurology, Neurosurgery and Psychiatry, $1947,10,107$.

24 Daly, D. D., and Barry, M. J., Psychosomatic Medicine, 1957, 19, 399.

${ }^{25}$ Elmquist, D., et al., Electroencephalography and Clinical Neurophysiology, in press.

${ }^{26}$ Wilkins, A., Andermann, F., and Ives, J., Electroencephalography and Clinical Neurophysiology, in press.

${ }^{27}$ Green, J. B., Epilepsia, 1971, 12, 225.

\section{Screening for Breast Cancer}

Breast cancer kills over 10000 women each year in England and Wales. The mortality rate has remained static over the past 25 years, and it is now evident that purely local treatment by surgery or radiotherapy rarely cures the disease. In most patients occult dissemination has taken place by the time the lump in the breast is first discovered. Recognition of this fact has led to the exploration of the needs for systemic therapy as part of primary treatment. ${ }^{1}$

An alternative approach is to detect the disease before such dissemination has occurred, and there is now evidence from the H.I.P. Study in New York that early detection of breast cancer by four episodes of annual screening by mammography and clinical examination is associated with a significant reduction of mortality from the disease. ${ }^{2}$ The results of the New York study have led to demands for the institution of a national screening service. These have meantime been resisted by the Department of Health and Social Security, whose opinion has been endorsed by members of the British Breast Group. On page 357 of this issue the Group reports on its recent discussions on the whole problem.

The foresight of the Health Departments in setting up 
pilot studies in breast screening is acknowledged, but the group suggests that there is need for a limited extension of this service. This should be within a co-ordinated programme of research designed to answer certain fundamental questions about cost effectiveness, risks, and the identification of women most likely to benefit. Screening clinics will need to be backed up by expert diagnostic and biopsy services, so that methods can be standardized and information of importance not lost.

Screening clinics apart, the group emphasizes the reduction in mortality which could come from the development of efficient services for the diagnosis and treatment of breast cancer, particularly if associated with an attempt to encourage women to seek treatment early. In times of fixed resources the cost and effect of all medical services must be considered, and large programmes of screening should not have priority over the establishment of an efficient service for the management of patients with established disease. The recent statement by the Minister of State that joint committees will be set up with the Medical Research Council to plan how these problems might be investigated indicates that the Health Departments are fully aware of the needs. ${ }^{3}$

\section{${ }^{1}$ Fisher, B., et al., New England fournal of Medicine, 1975, 292, 117. ference Proceedings, 1973, 663. \\ ${ }^{3}$ Hansard, House of Commons, 28 April, 1975, col. 9. \\ Neuropharmacological Aspects of Migraine}

${ }^{2}$ Shapiro, S., Strax, P., and Venet, L., in Seventh National Cancer Con-

Our understanding of migraine is hampered by lack of knowledge of its cause and by lack of precision in defining the condition. The pathophysiology of the attack is, perhaps, a simpler problem than that of aetiology and is increasingly agreed to be based on vasoconstriction followed by vasodilatation in cranial blood vessels, but even so the question of definition remains a stumbling block. Where does the simple vascular headache end and the entity migraine begin; and in particular are our pharmacological models of migraine simply those of any vascular headache?

In the past few years there has been no lack of biochemical and pharmacological candidates for a causative role. Any assessment of their claims to explain the condition should be made within the defined context of classical migraine-an aura of focal cerebral signs, commonly visual, leading to hemicrania often with nausea and vomiting-since it is from this that the accepted pathophysiology has been derived. Of the substances proposed as an initiator of the migraine attack serotonin has proved the most enduring. It is a vasoactive amine causing an increase in pulse rate and variable blood pressure changes, and it has vasoconstrictor, antidiuretic, and emetic effects. A number of observations link it with migraine. Increased urinary excretion of its main catabolites is found early in many migraine attacks. ${ }^{1}$ A slight rise in plasma serotonin levels has been found at the start of the migraine attack, but more convincingly a marked fall has been noted at the onset of the headache phase. ${ }^{2}$ These changes seem specific for migraine and are not found in other equally severe headaches.

Serotonin appears to be released from platelets, its main carrier cells in the blood, and a serotonin-releasing factor has been found in the plasma during a migraine attack. ${ }^{3}$ Reserpine, which is known to lower the plasma serotonin concentration, commonly causes an attack in those liable to migraine; while phenelzine, a monoamine oxidase inhibitor, increases endogenous serotonin production and is claimed to reduce the frequency and severity of attacks. Serotonin itself, given intravenously, may also relieve an attack. ${ }^{4}$ Methysergide, which remains one of the most effective prophylactics in migraine, may act by competing for certain serotonin receptor sites, thus allowing more to be available at others-and accounting for both the serotonin antagonist and simulating effects noted.

The picture is, however, less simple than at first appears. The potentiation of some adrenaline effects by serotonin, and the possible role of prostaglandins as a release factor, add complexity and widen the range of interpretation. While these observations, and the emetic and antidiuretic properties of serotonin, may seem to make a strong case and perhaps justify the phrase "low serotonin syndrome" for migraine, there are difficulties, cogently argued recently by Sjaastad..$^{5}$ Migraine attacks begin with vasoconstriction; serotonin is only a mild vasoconstrictor and the rise in its level at the start of an attack is only slight. Reserpine, besides reducing blood serotonin, also affects noradrenaline and dopamine activity. Methysergide, with large antiserotonin properties nevertheless appears to prevent and in some cases abort migraine attacks. Monoamine oxidase inhibitors are also effective, though there is some evidence that monoamine oxidase activity is already reduced in migraine sufferers. Moreover the serotonin levels are variable within a group of migraine patients in attacks, and in individual cases these may not be correlated with headache. These difficulties can be overcome by calling on the complexities of pharmacokinetics, but the place of serotonin as a main mediator of the migraine attack must still be regarded as sub judice.

${ }^{1}$ Sicuteri, F., Testi, A., and Anselmi, B., International Archives of Allergy and Applied Immunology, 1961, 19, 55.

2 Curran, D. A., Hinterberger, H., and Lance, J. W., Brain, 1965, 88, 997.

${ }^{3}$ Anthony, M., Hinterberger, H., and Lance, J. W., Research and Clinical Studies in Headache, 1968, 2, 29.

4 Kimball, R. W., Friedman, A. P., and Vallejo, E., Neurology, 1960, 10, 107. 5 Sjaastad, O., Acta Neurologica Scandinavica, 1975, 51, 200.

\section{Braille Anniversary}

Louis Braille, born in 1809 the son of a village cobbler near Paris, was blinded at the age of 3 years. He received some education in the village school, and at the age of 10 he was admitted to the National Institute for the Young Blind in Paris. Letters used for reading by the blind at this time were those of the ordinary Roman alphabet and made of lead or wood, so that they protruded above the surface.

During the year that Louis Braille enrolled at the institute a French artillery officer, Charles Barbien de la Serre, began to interest the Paris Academy of Sciences in a system of raised dots and dashes which he had invented to enable soldiers to communicate with each other while on night operations. Louis Braille worked on this system and at the age of 16,150 years ago, produced his system of reading based on six raised dots used in mathematical variation to express letters, punctuation signs, and mathematical signs. The system has been revised to some extent but basically remains the same as when it was introduced. He enlarged the system later to cover musical notation. Braille writers enable blind people to communicate by writing letters. Braille died in 1851 aged 42, and nine years passed before his raised type came into general use. 